\title{
Impacts of edge seal material on thermal insulation performance of a thermally resistive photovoltaic glazing: CFD research with experimental validation
}

\author{
Erdem Cuce \\ Recep Tayyip Erdogan University, Faculty of Engineering, Department of Mechanical Engineering, Rize, \\ Turkey \\ Recep Tayyip Erdogan University, Faculty of Engineering, Low/Zero Carbon Energy Technologies \\ Laboratory, Rize, Turkey \\ erdem.cuce@erdogan.edu.tr \\ ORCID:0000-0003-0150-4705
}

Arrived: 20.12.2018 Accepted: 21.01.2019 Published: 31.03.2019

\begin{abstract}
A novel design of photovoltaic (PV) glazing technology called TRPVG is introduced within the scope of this research, and thermal insulation performance of TRPVG for different edge seal materials is evaluated through a well-known and reliable commercial software ANSYS FLUENT. For a typical TRPVG configuration, CFD results are compared with the experimental data, and a good accordance is achieved. Then, different potential edge seal materials are considered for TRPVG technology in terms of their impacts on thermal bridging and hence overall heat transfer coefficient (U-value) of entire glazing. Besides the plastic based edge seals, which are widely utilized in fenestration products, thermal superinsulation materials like flexible aerogel are also considered in the research to analyze their potential effects for reducing the U-value range of TRPVG. A recent experimental research indicates a U-value of $1.10 \mathrm{~W} / \mathrm{m} 2 \mathrm{~K}$ in which unplasticised polyvinyl chloride (PVC-U) is considered as edge seal. The U-value from the CFD research for the said configuration is determined to be $1.19 \mathrm{~W} / \mathrm{m} 2 \mathrm{~K}$, which verifies the accuracy of the numerical analyses. Further investigations reveal that the U-value of TRPVG can be enhanced to $1.13 \mathrm{~W} / \mathrm{m} 2 \mathrm{~K}$ only if PVC-U edge seal is replaced with aerogel. This can be attributed to the competitively low thermal conductivity of PVC-U material $(0.19 \mathrm{~W} / \mathrm{mK})$ as an edge seal. The predicted U-values of TRPVG are reported to be $1.44 \mathrm{~W} / \mathrm{m} 2 \mathrm{~K}$ for polymer seal, $1.32 \mathrm{~W} / \mathrm{m} 2 \mathrm{~K}$ for glass fiber seal, $1.26 \mathrm{~W} / \mathrm{m} 2 \mathrm{~K}$ for polycarbonate seal, $1.24 \mathrm{~W} / \mathrm{m} 2 \mathrm{~K}$ for polyethylene seal, 1.20 $\mathrm{W} / \mathrm{m} 2 \mathrm{~K}$ for acrylic seal and $1.18 \mathrm{~W} / \mathrm{m} 2 \mathrm{~K}$ for epoxy seal.
\end{abstract}

Keywords: $\quad P V$ glazing, U-value, Edge seal material, Thermal insulation, CFD

Cite this paper as:

Cuce, E. Impacts of edge seal material on thermal insulation performance of a thermally resistive photovoltaic glazing: CFD research with experimental validation. Journal of Energy Systems, 2019; 3(1): 26-35, DOI: https://dx.doi.org/10.30521/jes.499794 


\section{INTRODUCTION}

Buildings are responsible for about $40 \%$ of total energy consumed worldwide. In this sense, building sector is considered as one the most sensitive fields for urgent mitigation of total world energy consumption figures in most of the developed and developing countries [1]. The dramatic role of buildings in global energy use can be ascribed to the insufficient thermal insulation features of existing building elements [2] as well as poor electrical and thermal efficiency ranges of conventional energy systems utilized in buildings [3]. As a consequence of this, there is a noticeable stimulation into alternative thermally resistive building materials [4] along with the energy-efficient, cost-effective and eco-friendly energy technologies toward low/zero carbon building standards [5]. Moreover, bioinspired strategies are evaluated for potential retrofit applications in buildings [6].

When a typical building envelope is taken into consideration, the poorest building element in terms of thermal insulation performance is identified as windows [7]. Approximately $60 \%$ of heat losses from building fabric are attributed to glazed areas. In this respect, a significant number of glazing technologies is in the center of interest to be able to meet the low/zero carbon performance figures proposed in latest building codes [8]. Among the all types of window technologies, PV glazing technology draws a remarkable attention of researchers especially within the last two decades owing to its multifunctional features. A typical PV glazing is capable of generating electricity when the external surface of the unit is subjected to sunlight [9]. PV glazing is widely preferred in modern architecture because of aesthetic aspects. It can be considered as an entire building element through building integrated PV and PV/Thermal (BIPV and BIPVT) applications. Especially BIPVT air collectors have a great potential to lead the fenestration market in the near future when optimum tilt angle is considered [10] and passive cooling strategies are utilized in the system [11]. Despite all of the said advantages of PV glazing technology, it has some shortcomings as well regarding thermal insulation performance, which is of vital importance in terms of overall performance merit of a glazing product. This handicap is considered as the most significant challenge for the commercialization process of the PV glazing technology [12]. The U-value of PV glazing products is not promising when compared to the multilayer glazing technology, which is dominant in market. Therefore, recent attempts are usually made for improving poor U-value range of PV glazing products through cost-effective and eco-friendly modifications.

Sun et al. [13] consider semi-transparent cadmium telluride (CdTe) in PV glazing concept, and evaluate the daylighting and energy performance of the product for different configurations. The maximum electrical efficiency of CdTe PV glazing is reported to be about $22 \%$. The average U-value of the product is determined to be $2.54 \mathrm{~W} / \mathrm{m}^{2} \mathrm{~K}$, which is competitive with air filled double glazed window. About $73 \%$ reduction in energy losses is achieved from the CdTe PV glazing as well as better daylighting performance in comparison with ordinary glazing. Cuce et al. [14] develop a novel design of PV glazing entitled heat insulation solar glass (HISG), and carry out several experimental studies on thermal insulation performance of the HISG unit. Semi-transparent amorphous silicon (a-Si) PV cells are utilized in the HISG unit with an electrical efficiency of about $9 \%$. Owing to the highly thermally resistive layers behind the PV cells, an overall U-value of $1.10 \mathrm{~W} / \mathrm{m}^{2} \mathrm{~K}$ is achieved from the HISG product. Energy generation performance of HISG is evaluated in another research conducted by Cuce et al. for actual operating conditions and under solar simulator [15]. The results reveal that HISG can generate more than $40 \mathrm{~W}$ electrical power for a solar intensity of $850 \mathrm{~W} / \mathrm{m}^{2}$ and for a PV glazing area of $0.66 \mathrm{~m}^{2}$. Lighting and energy saving performance of HISG are also investigated, and it is found that this novel PV glazing technology is capable of blocking $100 \%$ of UV light. In addition, enhanced indoor conditions are obtained by preventing the glare effects [16].

Ghosh et al. [17] propose a new design of PV glazing by incorporating the vacuum concept into the unit as a superior thermal resistance layer. Their experimental results demonstrate that a promising U-value $\left(0.80 \mathrm{~W} / \mathrm{m}^{2} \mathrm{~K}\right)$ can be achieved from the said design, which is sufficient to meet the latest low/zero 
carbon building standards. In comparison with the reference case of PV double glazing, $66 \%$ greater thermal resistance is obtained from the novel design. However, it needs to be noted that the said U-value is expected to deteriorate for longer operation periods due to probable losses in vacuum level. A similar attempt is carried out by Zhang et al. [18] through their novel design entitled vacuum PV insulated glass unit. A similar U-value is reported in their research for an entire product thickness of about $21 \mathrm{~mm}$. It is underlined that the novel PV glazing structure not only remarkably reduces the cooling loads of buildings but also provides comfortable indoor environments. Wang et al. [19] experimentally analyze the thermal insulation performances of two different PV glazing structure namely PV double skin facade and PV insulating glass unit. The experimental results show that the PV insulating glass unit has somewhat a lower U-value $\left(2.28 \mathrm{~W} / \mathrm{m}^{2} \mathrm{~K}\right)$ than PV double skin facade $\left(2.54 \mathrm{~W} / \mathrm{m}^{2} \mathrm{~K}\right)$. Zhang and $\mathrm{Lu}$ [20] conduct a simulation research to assess the overall thermal insulation performance of PV insulating glass unit under several climatic conditions. It is observed from the results that low-e integrated PV glazing shows better $\mathrm{U}$-value $\left(1.62 \mathrm{~W} / \mathrm{m}^{2} \mathrm{~K}\right)$ than the conventional $\mathrm{PV}$ glazing product with clear glass $\left(2.64 \mathrm{~W} / \mathrm{m}^{2} \mathrm{~K}\right)$.

Through the literature survey on PV glazing technology and potential strategies to reduce the U-value of PV glazing products in market, it is understood that the greatest part of efforts is essentially based on improving the thermal resistance of entire structure through additional layers provided behind such as inert gas or vacuum [21]. However, thermo-physical properties of materials utilized in PV glazing structure is also of vital importance in terms of overall thermal insulation performance. Replacing conventional support pillars inside Pilkington Spacia vacuum glazing with translucent aerogel and enhancing the U-value of vacuum glazing from 1.20 to $0.67 \mathrm{~W} / \mathrm{m}^{2} \mathrm{~K}$ is a good example of this [22]. Especially edge seals can play a dramatic role in thermal bridging effects, which can result in poorer thermal insulation performance figures than expected. The impacts of edge seal materials on the average U-value of a typical glazing product can be much more remarkable when the thermal resistance inside the glazing is incomparably greater than that of around edges [23]. A wide range of materials is utilized as edge seal material in glazing products such as acrylic, epoxy, PVC-U, low and high density polyethylene, glass fibre, polycarbonate, etc. However, there is no research conducted so far to analyze the said edge seal materials on the U-value of windows. Therefore, a CFD analysis is carried out within the scope of this research to evaluate the contributive effects of the said materials on thermal bridging for a case of novel PV glazing technology called TRPVG. For a reference case, CFD results are first compared with the experimental data, and following the accuracy justification, numerical research is repeated for the rest of the materials for the first time in literature.

\section{METHODOLOGY}

\subsection{Features of TRPVG}

TRPVG differs from the conventional PV glazing products in market in terms of several aspects such as very high thermal resistance which is competitive with argon filled triple glazed windows, selfcleaning feature owing to the $\mathrm{TiO}_{2}$ nano coating on the a-Si PV cells, thermally comfortable indoor conditions as a consequence of low-e coating integrated thermally resistive glass which yields to $100 \%$ blockage of UV and IR parts of incoming sunlight. Different configurations of TRPVG concept are devised, fabricated and tested through a comprehensive experimental and numerical optimization procedure. The numerical research is based on a reference design from a previous PV glazing technology called HISG. The constructional details of the reference TRPVG design are illustrated in Figure 1. TRPVG-Ar16 concept uses $16 \mathrm{~mm}$ thick argon as inert gas between a-Si PV cells and low-e integrated thermally resistive window pane. Argon as an inert gas provides excellent thermal resistance throughout the PV glazing structure. Low-e integrated thermally resistive window pane has a thermal conductivity of $0.96 \mathrm{~W} / \mathrm{mK}$. Low-e coating is slightly more thermally conductive $(1.20 \mathrm{~W} / \mathrm{mK})$, however, due to its 
negligible thickness, its impact on total heat transfer rate is ignored. PVC-U is utilized as edge seal material in the fabrication of TRPVG-Ar16. Thermal conductivity of PVC-U is $0.19 \mathrm{~W} / \mathrm{mK}$, which is satisfactory for such PV glazing applications. The poorest element in the construction in terms of thermal resistance is the a-Si PV module $(1.50 \mathrm{~W} / \mathrm{mK})$. $\mathrm{TiO}_{2}$ nano coating on the a-Si PV module enables selfcleaning feature, which is of vital importance for the tall buildings like skyscrapers. The aforesaid coating also reduces the reflection losses which yields to notable enhancements in electrical efficiency of the unit. TRPVG-Ar16 concept has an entire thickness of $28 \mathrm{~mm}$.

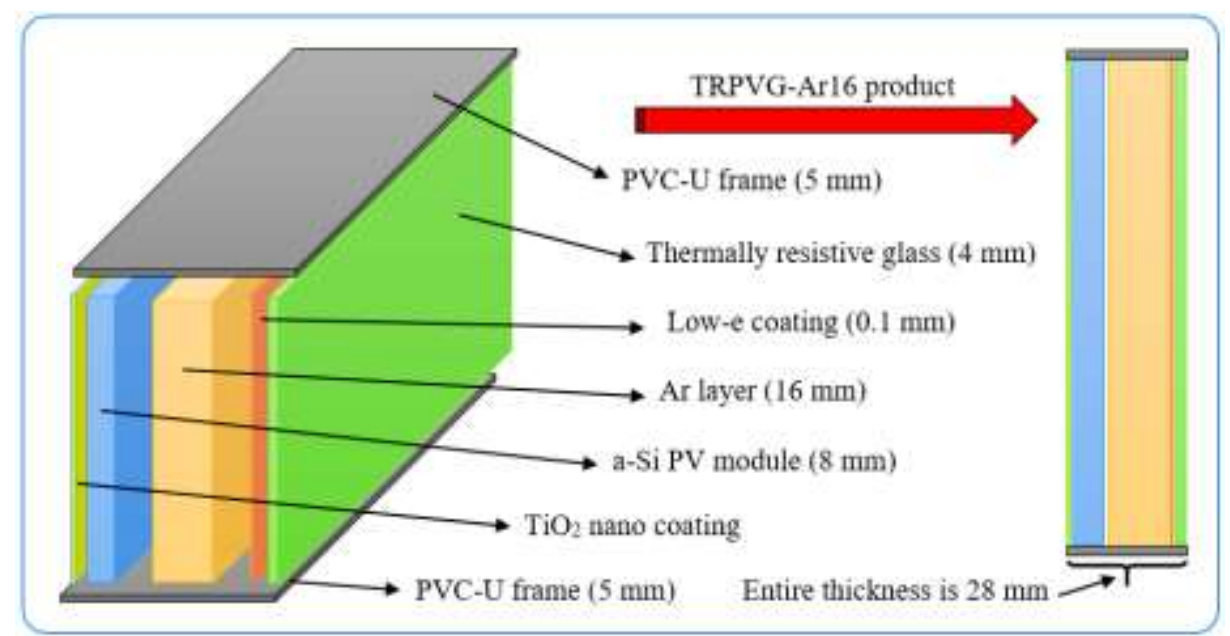

Figure 1. Constructional details of TRPVG-Ar16 product.

TRPVG-Ar16 is capable generating more than $100 \mathrm{~W}$ electrical power from per $\mathrm{m}^{2} \mathrm{PV}$ module area under standard test conditions $\left(1000 \mathrm{~W} / \mathrm{m}^{2}\right.$ solar intensity and $25{ }^{\circ} \mathrm{C}$ PV cell temperature). The production cost of TRPVG-Ar16 is slightly above $200 € / \mathrm{m}^{2}$, which is competitive with the market prize of conventional multilayer glazing products in Europe. The thorough thermo-physical properties of materials utilized in the fabrication of TRPVG-Ar16 is given in Table 1.

Table 1. Thermo-physical properties of materials inside TRPVG-Ar16

\begin{tabular}{lccc}
\hline & $\mathrm{d}\left(\mathrm{kg} / \mathrm{m}^{3}\right)$ & $\mathrm{c}_{\mathrm{p}}(\mathrm{J} / \mathrm{kgK})$ & $\mathrm{k}(\mathrm{W} / \mathrm{mK})$ \\
\hline a-Si PV module & 2330 & 703 & 1.50 \\
Ar layer & 1.6228 & 520.64 & 0.0158 \\
Thermally resistive glass & 2700 & 880 & 0.96 \\
Low-e glass & 2550 & 800 & 1.20 \\
PVC-U & 1400 & 900 & 0.19 \\
\hline
\end{tabular}

In the fabrication of any type of PV glazing product, edge seal materials are utilized for thermal insulation and sealing purposes. Within the scope of the research project, several edge seal materials are considered from conventional to superinsulation material category. However, a reference product is also produced from PVC-U to justify the accuracy of the CFD analyses as experimental U-values on similar designs are available in literature.

\subsection{CFD analysis}

Within the scope of CFD analyses, a well-known, reliable and commercially available software ANSYS FLUENT is utilized. The geometry is constructed in GAMBIT which is in good accordance with the software. A 2D model is structured which is successful enough to simulate the heat transfer mechanisms within the PV glazing. TRPVG-Ar16 is subjected to natural convection internally and forced convection externally through internal and external surfaces, respectively. The indoor and outdoor temperatures and heat convection coefficients as well as thermo-physical properties of environmental chamber air considered in the CFD analyses are presented in Table 2. TRPVG-Ar16 is assumed to have adiabatic boundary conditions at the edges, however, heat transfer through the edge seal material is studied in the research, which is basically the goal of this work. By considering different edge seal materials, their 
potential impacts on thermal bridging are numerically analyzed. PRESTO approach is preferred as a consequence of selecting pressure-based solver in the modelling of natural convection inside argon medium. Rectangular mesh is structured in the CFD analyses, and mesh-independent solution is achieved. Convergence criteria is selected to be $10^{-4}$ which is adequate for such a model. Convergence is easily secured by controlling the under-relaxation factors during the iteration process.

Table 2. Indoor and outdoor convection parameters utilized in CFD research

\begin{tabular}{lccc}
\hline & $\mathrm{d}\left(\mathrm{kg} / \mathrm{m}^{3}\right)$ & $\mathrm{c}_{\mathrm{p}}(\mathrm{J} / \mathrm{kgK})$ & $\mathrm{k}(\mathrm{W} / \mathrm{mK})$ \\
\hline Environmental chamber air & 1.2250 & 1006.43 & 0.0242 \\
& $\mathrm{~h}\left(\mathrm{~W} / \mathrm{m}^{2} \mathrm{~K}\right)$ & \\
\hline Indoor air & 5 & $\mathrm{~T}\left({ }^{\circ} \mathrm{C}\right)$ \\
Outdoor air & 25 & 25 \\
\hline
\end{tabular}

\subsection{U-value analysis}

The calculation of U-value for the TRPVG-Ar16 design is based on the numerical values produced by ANSYS FLUENT software. In this respect, total heat transfer rate across the PV glazing is determined through the reports section of the software. Then, through the surface integrals interface, area-weighted average surface temperatures are specified for both internal and external surfaces. Total heat transfer rate is divided by surface area of PV glazing and temperature difference between internal and external surfaces, which yields to the U-value of entire TRPVG-Ar16.

\section{RESULTS and DISCUSSIONS}

In this research, several potential edge seal materials are considered for TRPVG-Ar16 in terms of their effects on thermal bridging and thus the U-value of entire PV glazing. Prior to demonstrating the extended results, an accuracy justification is conducted through a reference case study in which PVC-U material is considered at the edges for sealing and thermal insulation purposes. For the thermo-physical properties of materials given in Table 1, and for the convection parameters listed in Table 2, contours of static temperature inside TRPVG-Ar16 are achieved as shown in Figure 2. It is understood from the data that the right hand side of the contour image is subjected to the indoor environment whereas the left hand side is exposed to outdoor conditions.

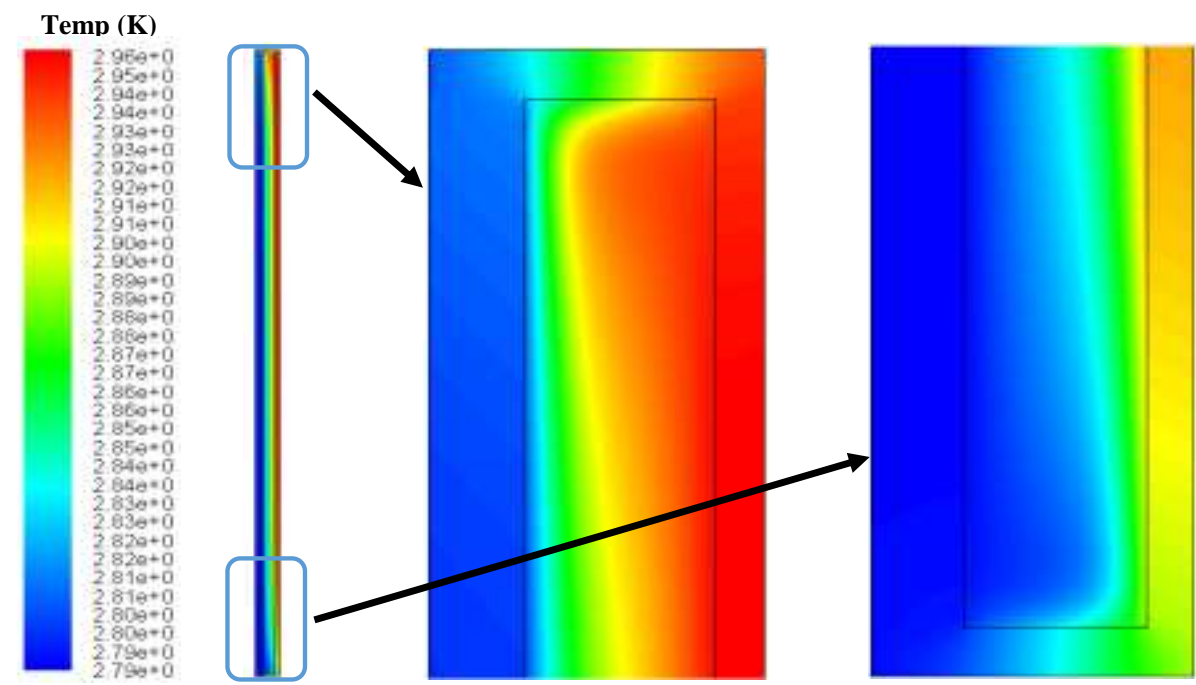

Figure 2. Contours of static temperature inside TRPVG-Ar16 and thermal behavior of the product. 


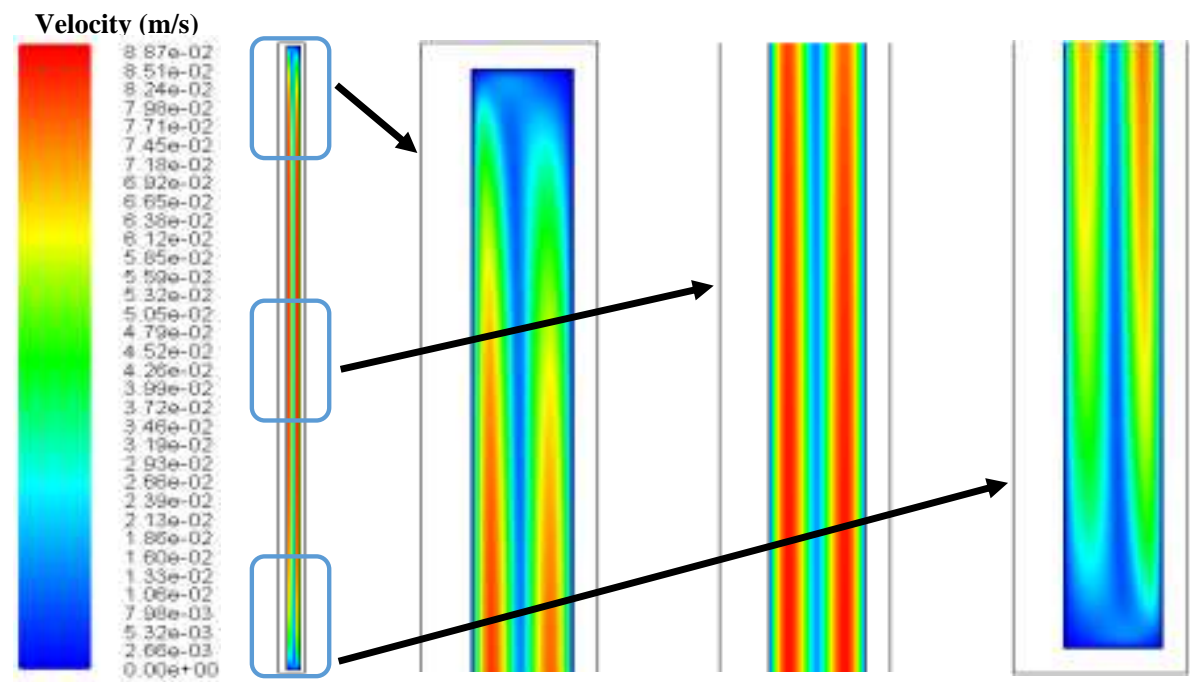

Figure 3. Contours of velocity magnitude inside TRPVG-Ar16.

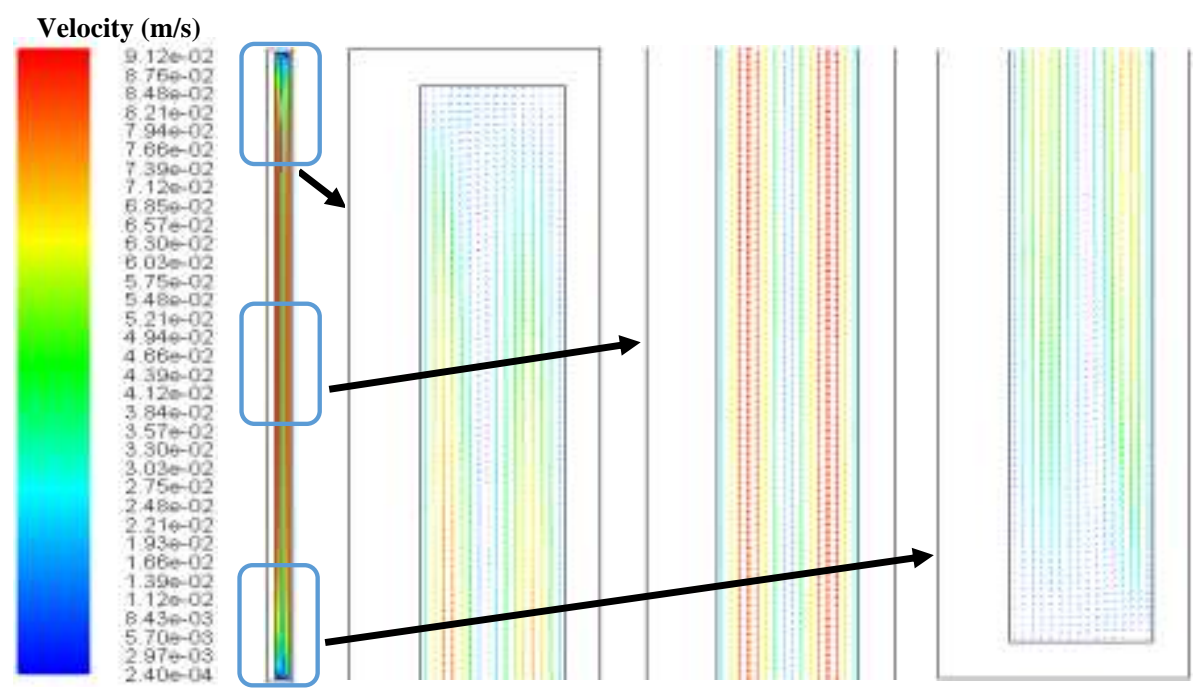

Figure 4. Natural convection effects and velocity vectors inside TRPVG-Ar16.

The contours of velocity magnitude inside TRPVG-Ar16 and the thermal behavior of the product are illustrated in Figure 3. It is observed from the data that noticeable natural convection effects take place within $16 \mathrm{~mm}$ thick argon medium as expected. However, owing to the somewhat high viscosity values of argon at room temperature, impacts of natural convection on total heat transfer rate across the product remain limited. Around central parts of TRPVG-Ar16, natural convection effects become maximum as predicted, and corresponding velocity value for the said parts are shown in Figure 4. The results indicate that the greatest velocity inside TRPVG-Ar16 is about $0.0912 \mathrm{~m} / \mathrm{s}$, which is reported around center. Natural convection effects are negligible around the edges which are covered with PVC-U material.

For the said boundary conditions, the total heat transfer rate from TRPVG-Ar16 is numerically determined to be $16.8873 \mathrm{~W}$ as shown in Figure 5. Following the determination of total heat transfer rate, the average temperatures of internal and external surfaces of TRPVG-Ar16 are specified as depicted in Figure 6. 


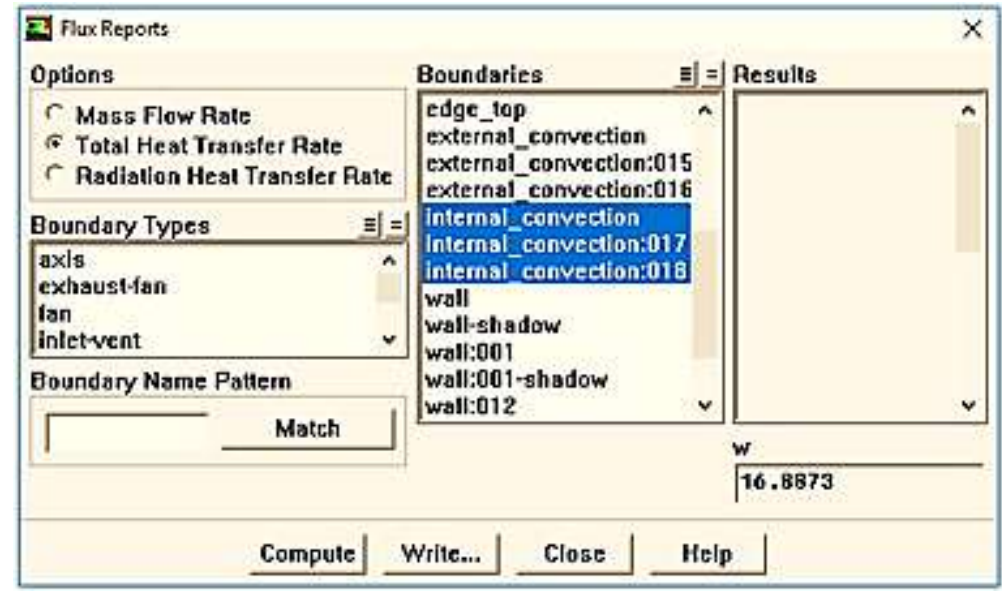

Figure 5. Total heat transfer rate across TRPVG-Arl6 product.
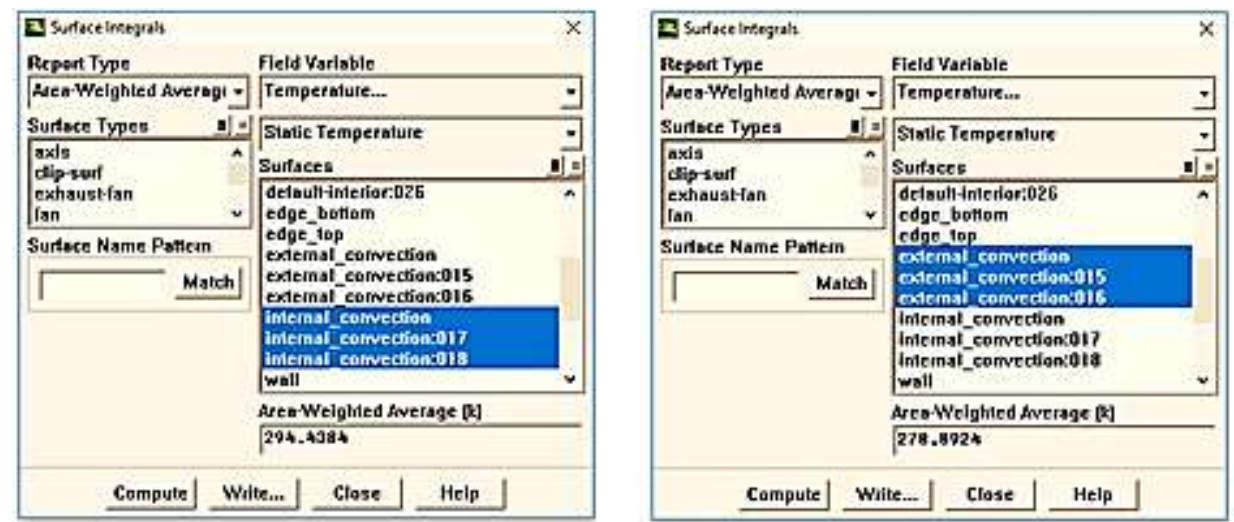

Figure 6. The average internal and external surface temperatures of TRPVG-Ar16 product.

The average internal surface temperature is determined to be $294.4384 \mathrm{~K}$ whereas it is $278.8924 \mathrm{~K}$ for the external surface. In other words, the temperature difference across TRPVG-Ar16 product is reported to be $15.5460 \mathrm{~K}$. Total surface area of the product is $0.91 \mathrm{~m}^{2}$. By a simple implementation of Newton's cooling law, the numerical U-value of TRPVG-Ar16 can be calculated as follows:

$$
\begin{gathered}
Q=U A \Delta T \\
U=Q / A\left(T_{\text {int }}-T_{\text {ext }}\right) \\
U=16.8873 / 0.91(294.4384-278.8924) \\
U=1.19 \mathrm{~W} / \mathrm{m}^{2} \mathrm{~K}
\end{gathered}
$$

The numerical U-value from the CFD analysis $\left(1.19 \mathrm{~W} / \mathrm{m}^{2} \mathrm{~K}\right)$ is compared with a reference product in recent literature called HISG which has similar configuration details. The experimental U-value of the reference product is reported to be $1.10 \mathrm{~W} / \mathrm{m}^{2} \mathrm{~K}$ [24], which is in good accordance with the numerical U-value achieved from the CFD research. The aforesaid experimental study is a typical application of 
co-heating test procedure in literature [14]. In a typical co-heating test, the U-value of any building element is experimentally determined through hot box and environmental chamber test system. Hot box and environmental chamber represent the indoor and outdoor conditions in winter time, respectively. Hot box temperature is usually adjusted to $25^{\circ} \mathrm{C}$, while environmental chamber is set to $5{ }^{\circ} \mathrm{C}$. Heat flow across the building element is measured by a sensitive heat flux sensor. In addition, internal and external surface temperature of the building element are determined via sensitive $\mathrm{T}$ or $\mathrm{K}$ type thermocouples. Through Newton's cooling law, U-value of the building element is specified. Co-heating test procedure is a well-known and reliable method in literature to investigate the thermal insulation performance of any type of building element.

Following the accuracy justification of the CFD analyses, different edge seal materials are investigated for novel TRPVG-Ar16 concept for the first time in literature in terms of their potential influences on the U-value of entire glazing. It is clear from the literature that plastic based edge seals are commonly utilized in fenestration products. Within the scope of this research, not only the said plastic type materials but also thermal superinsulation materials like flexible aerogel are considered for edge sealing, and the $\mathrm{U}$-value range of TRPVG-Ar16 is numerically evaluated for each case.

The CFD analyses are repeated for different edge seal materials for the thermal conductivity range of $0.01-10 \mathrm{~W} / \mathrm{mK}$. The thermal conductivity of $0.01 \mathrm{~W} / \mathrm{mK}$ [25] refers to the greatest thermal resistance at the edges which is provided by aerogel [26], whereas $10 \mathrm{~W} / \mathrm{mK}$ corresponds to the poorest thermal resistance feature of polymer edge seal. The numerical U-values achieved from the CFD research are demonstrated in Figure 7.

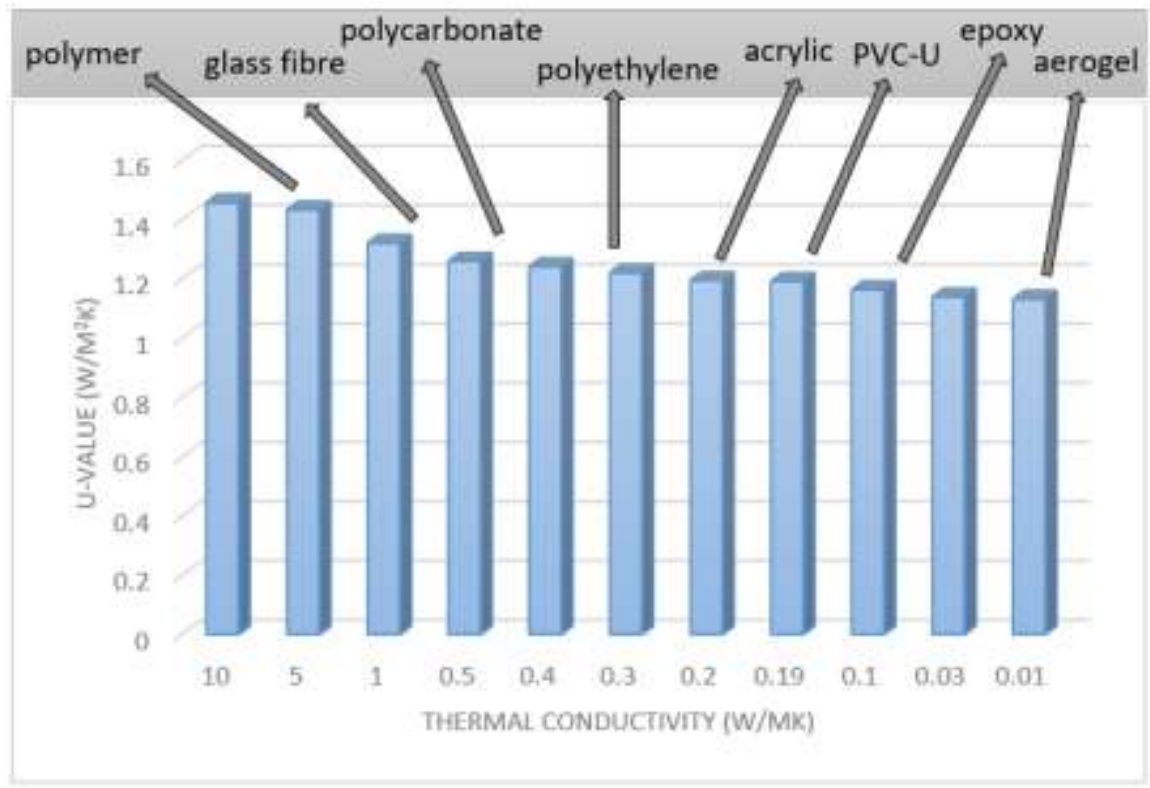

Figure 7. The U-value of TRPVG-Ar16 for different edge seal materials.

The estimated U-values of TRPVG-Ar16 are found to be $1.44 \mathrm{~W} / \mathrm{m}^{2} \mathrm{~K}$ for polymer seal, $1.32 \mathrm{~W} / \mathrm{m}^{2} \mathrm{~K}$ for glass fiber seal, $1.26 \mathrm{~W} / \mathrm{m}^{2} \mathrm{~K}$ for polycarbonate seal, $1.24 \mathrm{~W} / \mathrm{m}^{2} \mathrm{~K}$ for polyethylene seal, $1.20 \mathrm{~W} / \mathrm{m}^{2} \mathrm{~K}$ for acrylic seal and $1.18 \mathrm{~W} / \mathrm{m}^{2} \mathrm{~K}$ for epoxy seal. If aerogel as a thermal superinsulation material is considered at the edges, the overall U-value of TRPVG-Ar16 is only enhanced to $1.13 \mathrm{~W} / \mathrm{m}^{2} \mathrm{~K}$. Due to the remarkably higher unit cost of aerogel compared to the other potential edge seal materials, it is recommended to utilize epoxy or PVC-U in the entire design of novel TRPVG technology. Compared to the polymer seals, epoxy is determined to show $18 \%$ better thermal resistance, which is of vital importance to note. 


\section{CONCLUSION}

PV glazing products in market are usually poor in terms of thermal insulation performance due to their remarkably high U-value ranges. A novel PV glazing technology called TRPVG-Ar16 is introduced, and its thermal insulation ability is numerically analyzed through a well-known and reliable commercial software ANSYS FLUENT. Edge seal materials' thermo-physical properties play a key role in overall heat transfer coefficient of PV glazing. Therefore, different edge seals are considered for TRPVG-Ar16, and the impacts of edge seal material on thermal bridging are numerically investigated. The results reveal that epoxy, PVC-U and acrylic show the best performance when thermal resistance and cost figures are taken into account at the same time. Polymer edge seals demonstrate the poorest thermal insulation feature as a consequence of their somewhat high thermal conductivity range. $18 \%$ lower Uvalue can be achieved from TRPVG-Ar16 if epoxy is utilized for edge sealing instead of polymer.

\section{Acknowledgments}

The author gratefully acknowledges the financial support of TÜBİTAK (The Scientific and Technological Research Council of Turkey) through the project grant of 216M531.

\section{REFERENCES}

[1] Cuce, E. Development of innovative window and fabric technologies for low-carbon buildings. Ph.D. Thesis, The University of Nottingham, Nottingham, United Kingdom, 2014.

[2] Volf M, Lupíšek A, Bureš M, Nováček J, Hejtmánek P, Tywoniak J. Application of building design strategies to create an environmentally friendly building envelope for nearly zero-energy buildings in the central European climate. Energy and Buildings 2018; 165: 35-46.

[3] Cuce PM, Cuce E. Toward cost-effective and energy-efficient heat recovery systems in buildings: Thermal performance monitoring. Energy 2017; 137: 487-494.

[4] Berardi U. Aerogel-enhanced systems for building energy retrofits: Insights from a case study. Energy and Buildings 2018; 159: 370-381.

[5] Cuce E, Cuce PM, Besir AB. Greenery systems toward low/zero carbon buildings. Chapter in Low Carbon Transition - Technical, Economic and Policy Assessment. London, United Kingdom, InTechOpen, 2018; 2950.

[6] Cuce E, Nachan Z, Cuce PM, Sher F, Neighbour GB. Strategies for ideal indoor environments towards low/zero carbon buildings through a biomimetic approach. International Journal of Ambient Energy 2019; 40(1): 86-95.

[7] Cuce E. Accurate and reliable U-value assessment of argon-filled double glazed windows: A numerical and experimental investigation. Energy and Buildings 2018; 171: 100-106.

[8] Jelle BP, Hynd A, Gustavsen A, Arasteh D, Goudey H, Hart R. Fenestration of today and tomorrow: A stateof-the-art review and future research opportunities. Solar Energy Materials and Solar Cells 2012; 96: 1-28.

[9] Cuce E. Toward multi-functional PV glazing technologies in low/zero carbon buildings: Heat insulation solar glass - Latest developments and future prospects. Renewable and Sustainable Energy Reviews 2016; 60: 1286-1301.

[10] Cuce E, Cuce PM. Tilt angle optimization of building-integrated photovoltaics (BIPVs) for cooler operating temperatures. MEGS IV Annual Conference, Public Engagement with Energy. 12-13 September 2013, Loughborough, United Kingdom.

[11] Cuce PM, Cuce E. Passive cooling of building-integrated photovoltaics (BIPVs) for better electrical performance. MEGS IV Annual Conference, Public Engagement with Energy. 12-13 September 2013, Loughborough, United Kingdom.

[12] Cuce E. Recent developments on multi-functional PV glazing technologies: Heat insulation solar glass. Fifteenth International Conference on Sustainable Energy Technologies. 19-22 July 2016, Singapore. 
[13] Sun Y, Shanks K, Baig H, Zhang W, Hao X, Li Y, He B, Wilson R, Liu H, Sundaram S, Zhang J. Integrated semi-transparent cadmium telluride photovoltaic glazing into windows: Energy and daylight performance for different architecture designs. Applied Energy 2018; 231: 972-984.

[14] Cuce E, Young CH, Riffat SB. Thermal performance investigation of heat insulation solar glass: A comparative experimental study. Energy and Buildings 2015; 86: 595-600.

[15] Cuce E, Young CH, Riffat SB. Performance investigation of heat insulation solar glass for low-carbon buildings. Energy Conversion and Management 2014; 88: 834-841.

[16] Cuce E, Young CH, Riffat SB. Thermal insulation, power generation, lighting and energy saving performance of heat insulation solar glass as a curtain wall application in Taiwan: A comparative experimental study. Energy Conversion and Management 2015; 96: 31-38.

[17] Ghosh A, Sundaram S, Mallick TK. Investigation of thermal and electrical performances of a combined semitransparent PV-vacuum glazing. Applied energy 2018; 228: 1591-600.

[18] Zhang W, Lu L, Chen X. Performance evaluation of vacuum photovoltaic insulated glass unit. Energy Procedia 2017; 105: 322-326.

[19] Wang M, Peng J, Li N, Yang H, Wang C, Li X, Lu T. Comparison of energy performance between PV double skin facades and PV insulating glass units. Applied Energy 2017; 194: 148-160.

[20] Zhang W, Lu L. Overall energy assessment of semi-transparent photovoltaic insulated glass units for building integration under different climate conditions. Renewable Energy 2019; 134: 818-827.

[21] Cuce E, Cuce PM. Smart retrofit solutions of buildings toward a low carbon world. Energy Research Journal 2018; 9: 77-86.

[22] Cuce E, Riffat SB. Aerogel-assisted support pillars for thermal performance enhancement of vacuum glazing: a CFD research for a commercial product. Arabian Journal for Science and Engineering 2015; 40(8): 2233 2238

[23] Lee W, Kang J, Cho SW. A New Structure of Vacuum Insulation Glazing for Edge Effect Reduction: A Parametric Study. International Journal of Precision Engineering and Manufacturing 2018; 19(3): 447-452.

[24] Cuce E, Cuce PM, Riffat SB. Novel glazing technologies to mitigate energy consumption in low-carbon buildings: A comparative experimental investigation. International Journal of Energy Research 2016; 40: 537-549.

[25] Cuce E, Cuce PM, Wood CJ, Riffat SB. Toward aerogel based thermal superinsulation in buildings: A comprehensive review. Renewable and Sustainable Energy Reviews 2014; 34: 273-299.

[26] Buratti C, Cuce E, Merli F, Moretti E. Thermal and acoustic properties of aerogels: Preliminary investigation of the influence of granule size. Eighth International Conference on Sustainability in Energy and Buildings. 11-13 September 2016, Turin, Italy. 